\title{
Lasting Peace or Temporary Calm? Rebel Group Decapitation and Civil War Outcomes
}

\author{
Kirssa Cline Ryckman \\ School of Government and Public Policy \\ University of Arizona \\ 315 Social Sciences, \\ Tucson, AZ, USA 85721 \\ klcline@email.arizona.edu
}

July 2017

\section{Acknowledgements:}

This paper was previously presented at the 2017 International Studies Association annual convention in Baltimore, MD. Thanks to my fellow panelists and audience members as well as the editors of CMPS and the anonymous reviewers for their useful comments and suggestions. Replication files can be found on my Dataverse page: https://dataverse.harvard.edu/dataverse/kcryckman

\section{Abstract}

Existing research has found that killing or capturing rebel group leaders can lead to the termination of civil wars. This paper considers the quality of those terminations, examining how wars end and whether this produces a lasting peace or only a temporary reprieve from violence. Decapitation is expected to weaken rebel groups, shifting the balance of power to the government; however, results suggest that killing or capturing a rebel group leader tends to produce termination through inactivity rather than outright government victories. Decapitation is also found to have no effect on the chances of civil war recurrence. This suggests that the removal of rebel group leaders is effective primarily as a short-term strategy that does not tend to generate a lasting peace.

\section{Introduction}

Leadership decapitation has become a cornerstone of counterterrorism policy (Abrahms and Mierau, 2015), typified by the capture and death of al Qaeda's Osama bin Laden, and is likewise a prominent strategy used against criminal organizations (Calderón et al., 2015; Phillips, 2015) and rebel groups (Tiernay, 2015). While this strategy is widely used, there continues to be significant debate surrounding the effectiveness of leadership decapitation. Some find that it reduces the frequency and lethality of 
terror attacks and that it can lead to the end of insurgencies and civil wars (Johnston, 2012; Johnston and Sarbahi, 2016; Tiernay, 2015). Others find that there is no real impact of targeted killings (Cronin, 2011; Hafez and Hatfield, 2006; Hepworth, 2014), and other still find that targeted killings actually serve to increase violence (Abrahms and Potter, 2015; Calderón et al., 2015; Jordan, 2009).

One source of disagreement likely emanates from the wide variety of campaigns, targets, and actions that are considered within the literature, and there is also little consensus on what determines success (see Carvin, 2012). To better isolate the effect of leadership decapitation, I limit this study to the targeted killing or capture of the top leader of a rebel group. This is done for a number of reasons. As argued by Fortna (2015), civil wars provide a set of cases that have a more clearly defined end point as compared to terror campaigns. ${ }^{1}$ This, along with conflict recurrence, provides a clearer measure of success. Rebel groups, and by extension their top leaders, are also likely to be more visible given their necessary interactions with government security forces, allowing for nearly all civil wars to be included in the study. There is also variation in both the occurrence of leadership decapitation and in different termination types, which allows for the examination of whether civil wars are more likely to end as well as how they are likely to end following decapitation. There are also relatively few studies that specifically consider the case of civil war and decapitation of rebel group leaders outside of work done by Johnston (2012) and Tiernay (2015). Given the prevalence of civil conflict, its destructive nature, and its high rates of recurrence, understanding strategies that can be used to end these conflicts is a worthwhile endeavor.

"Decapitation" is defined here as the successful kill or capture of a group's top leader. ${ }^{2}$ Rebel groups are defined as formally organized, non-state groups that are actively fighting against the government of a state, generating at least 25 battle-related deaths per year (Gleditsch et al., 2002). Terror groups, by contrast, may only target civilians or property and are not necessarily pursuing a larger campaign. Despite these differences, there is considerable overlap between terror and rebel groups: Stanton (2013) estimates that about $45 \%$ of rebel groups use terrorism, while Findley and Young (2012) estimate that up to $60 \%$ of all terror attacks are carried out by a rebel group. In addition, within the terrorism decapitation literature there is often an implicit assumption that the group is engaging in a wider campaign of violence, as the question being assessed is whether removing a group's leader will degrade its military or operational effectiveness (e.g., Price 2012, 24).

When studies are limited to the top leaders of rebel groups, there is some agreement that leadership decapitation works. Both Johnston (2012) and Tiernay (2015) find that removing the leader of an 
insurgency shortens the conflict, can promote government victory, and reduces the frequency and lethality of terror attacks. There is also case study evidence that leadership decapitation against the Shining Path and the FARC reduced attacks (D'Alessio et al., 2014; Morehouse, 2014). The goal of this paper is to better understand the effect of leadership decapitation on civil war outcomes, and in particular, to examine what might be considered the quality of those terminations.

To address this question, the effect of leadership decapitation is considered on war termination and conflict recurrence. It is first expected that leadership decapitation will reduce the effectiveness of a rebel group. Existing studies focus on the relevance of leadership, organizational structure, and resource flows as important mitigating factors in whether decapitation will be effective (Abrahms and Potter, 2015; Byman, 2006; Cronin, 2011; Jenna Jordan, 2014; Price, 2012). For most insurgencies, decapitation is expected to militarily degrade the group, which leads to the expectation that removing a rebel group leader will lead to the termination of conflict in a way that is beneficial to the government. The longterm implications of decapitation are also considered to determine if conflicts that end via decapitation are likely to recur in comparison to conflicts that do not involve leadership decapitation. While decapitation is expected to degrade a group, absent a government victory, there is little to suggest that insurgencies will be decimated to the point of no return. As the underlying grievance is likely to be unresolved and the infrastructure of insurgency potentially salvageable, groups can reform, restructure, and recruit new members following decapitation. This leads to the expectation that decapitation in general will not reduce the chances of recurrence.

In the next section, I examine the existing literature on leadership decapitation in general, followed by an examination of civil wars in particular. Expectations related to war termination and recurrence are drawn based on this discussion and are tested using data from the Armed Conflict Dataset (Gleditsch et al., 2002) as well as data based on work from Tiernay (2015) and Johnston (2012) on rebel group decapitation, which is supplemented with data that I collected to expand the time coverage of the data. The results indicate that leadership decapitation shortens wars in a way that is beneficial to the government; however, rather than increasing the chances of government victory, I find that decapitation only significantly increases the chances of low activity outcomes, where conflict activities are significantly reduced such that the war is no longer considered active. Tests of civil war recurrence point to the short-term effects of leadership decapitation, as wars that end with leadership removal are no less likely to recur. I conclude with a discussion of these results as well as a consideration of policy implications. 


\section{The Effectiveness of Leadership Decapitation}

There is considerable controversy over the effectiveness of leadership decapitation among terrorism scholars. Of the studies that consider the effectiveness of decapitation across many cases, results typically suggest that removal of group leaders has little effect. Mannes (2008) examines the removal of the top or second-in-command leader of terror organizations, finding that decapitation had no effect in general, with limited evidence that it can increase the severity of attacks for religious organizations. Jordan (2009) focuses on the removal of top leaders and the upper management of terror groups, finding that decapitation is ineffective particularly in older, larger, religious, and separatist groups. She finds that decapitation leads to neither organizational death nor degradation of these groups. Terror groups are included in the study only if a successful removal of a leader occurs, however, and as such there is no variation on the independent variable in the main analysis, which makes it difficult to determine the effectiveness of decapitation. Cronin $(2011,33)$ considers a series of case studies, concluding that there is little connection between the removal of a group's leader and the end of a terror campaign.

There are also a number of specific cases that have received considerable attention. This includes Israel, which adopted a policy of targeted assassinations against Palestinians during the Second Intifada. From September 2000 to June 2004, Israel carried out approximately 151 assassinations, primarily through airstrikes (Hafez and Hatfield, 2006). Studies by Kaplan et al. (2005) and Hafez and Hatfield (2006) find that these targeted assassinations had no real effect on Palestinian attacks, and may have even increased recruitment. Byman (2006), however, argues that the lethality of Hamas attacks during this period sharply declined. Zussman and Zussman (2006) find that targeting senior military leaders had a positive effect on the Israeli stock market, but targeting senior political leaders had a negative impact; however, Kober (2007) argues the opposite, that attacking political and spiritual leaders led to the end of the Second Intifada, while attacking military leaders had no real effect. Findings are decidedly mixed.

As data have become available on the US drone campaign carried out in Pakistan and Afghanistan, research has increasingly examined the effectiveness of targeted killings in these theaters. Johnston and Sarbahi (2016) find that drone strikes led to a decline in the incidence and lethality of terror attacks, which is complemented by findings from Javier Jordan (2014) and Wilner (2010) who argue that drone strikes have contributed to the overall degradation of al Qaeda Central and the Taliban, respectively. Hepworth (2014) finds no evidence of retaliation after the killing of top-tier al Qaeda leaders. Abrahms and Potter (2015) as well as Abrahms and Mierau (2015) find that drone strikes led to a decline in 
attacks against military targets in the Afghanistan-Pakistan tribal regions, but that they also increased indiscriminate targeting. Jenna Jordan (2014) argues that the attacks against al Qaeda are ineffective and likely to be counterproductive. Thus even among scholars examining the same cases, there is considerable disagreement.

Taken together, the literature on terrorism faces issues related to case selection and differing concepts, as noted by Carvin (2012). The two cases that have received the most attention - Israel and the US drone campaign in Pakistan and Afghanistan - focus on robust organizations that are not likely to represent the average terror group. Likewise, studies across multiple cases either find no real results or can only speak to the effectiveness of particular decapitation attempts. In considering civil wars, some of these issues are mitigated, and decapitation appears to be a more viable strategy.

\section{The Effect of Decapitation on Civil Wars}

While there has been little consensus regarding the effectiveness of leadership decapitation on terrorism, when the focus is shifted to cases of civil war or guerrilla insurgencies, results from Tiernay (2015) and Johnston (2012) suggest that decapitation tends to work. Both studies examine a large set of civil wars and insurgencies, respectively, which widens the organizational profile that has typically been studied by terrorism scholars. Their findings suggest that killing or capturing rebel leaders increases the probability of war termination. Johnston (2012) also finds that wars that end in leadership decapitation are more likely to end in government victory, and that both the lethality and frequency of attacks decrease after successful leadership decapitation.

In addition to these large- $N$ studies, a series of case studies have also been conducted to explore the effects of leadership removal on group activity. D'Alessio et al. (2014) examine the Shining Path's war against Peru, finding that the frequency and lethality of attacks decreased after the capture of Abimael Guzman, the group's leader. Morehouse (2014) examines the targeted killing program in Colombia against leaders at any level of the FARC, finding that killings decreased the number of FARC attacks, although it had no effect on the lethality of those attacks. Analyses of government victories, such as Sri Lanka's defeat of the Liberation Tigers of Tamil Eelam (LTTE), also point to the importance of leadership decapitation. The death of Prabhakaran, the founder and leader of the LTTE, along with most high-level military and political leaders, contributed to the group's full defeat in 2009 (Uyangoda, 2010). Conversely, Morehouse (2015) finds that there was limited influence of leadership decapitation carried out by Russia against the Chechens. While there continues to be variation in the effectiveness of 
leadership decapitation among various cases, across the body of existing work there is reason to believe that this strategy can be effective.

In spite of these empirical findings, there is relatively little theorizing about why killing or capturing a group's leader should work. Rather, the general hypothesis presented is that the removal of a leader will reduce the military capacity of a group. To further explore why the removal of a rebel leader can reduce the group's effectiveness, three mechanisms are drawn from the terrorism literature that can be applied to cases of civil conflict: leadership, organizational structure, and popular support/material resources. These theoretical mechanisms are discussed to build support for the expectations that follow, namely that decapitation will, all else equal, tend to shorten civil conflicts in a way that is beneficial to the government.

\section{Leadership}

Price (2012) argues that leadership is particularly important for terror groups due to the level of control that they have over their organizations. They are not beholden to a board of directors or to a superior, unless they are state sponsored, which leaves leaders able to act with relative freedom. They are additionally able to influence every aspect of their group, giving them a great amount of power over how their organization functions. This renders individual leaders important to the effective functioning of the group, with potentially serious consequences on the group's ability to function if the leader is removed. Leaders of violent groups are also often charismatic individuals who were able to inspire the creation of and membership in the group, while leaders of values-based organizations must also present (and in some cases create) the group's ideology and guiding principles.

Applying this logic to rebel groups, this suggests there are two primary roles for leaders: organizational control and inspirational direction. Freeman (2014) argues that the greater inspirational and operational role a leader has within a group, the more that leader will matter to the group's survival. Taken together, this suggests that decapitation is likely to decrease an insurgency's ability to function in the short-term given the overall importance of leaders to rebel groups, especially if the leader has a central inspirational or operational role.

\section{Organizational Structure}

In addition to leadership, a number of studies also point to the importance of organizational structure, focusing on centralization and bureaucratization. First, decentralized organizations are expected to be more resilient than highly centralized organizations (Byman, 2006; Carley et al., 2002; Kenney et al., 
2016). The case studies on Peru, Colombia, and Russia each discuss the role of centralization, presenting evidence that centralized organizations face a greater risk from decapitation. Both the Shining Path and the FARC are known as being centralized, and in both cases the removal of group leaders decreased the group's productivity (D'Alessio et al., 2014; Morehouse, 2014). Morehouse (2015), on the other hand, argues that the Chechen separatists are decentralized, made up of a number of Chechen organizations with often varied and unclear command structures. This helps to explain why the targeted killing of Chechen leaders had no real effect on attacks carried out by the Chechen militants. ${ }^{3}$ Second, Jenna Jordan (2014) argues that groups that are bureaucratized are less susceptible to decapitation attempts. These groups are "diversified, have a clear division of administrative responsibilities and functions, [and] follow rules and procedures," which promote stability and resilience (11). This can guide organizations through periods of leadership turnover as bureaucratized groups are more likely to have a plan for leadership succession, and diversification can strengthen resource generation and group funding. In sum, this suggests that organizations that are decentralized or bureaucratized should be better able to withstand the removal of their leader, while centralized and non-institutionalized groups will be prone to degradation. There is reason to believe, however, that groups will actively resist institutionalization and bureaucratization in order to maintain secrecy and make information collection on their organization more difficult (Johnston, 2012; Shapiro, 2013), which would render groups more susceptible to leadership removal attempts. If a group is centralized or non-institutionalized, decapitation is expected to have a greater impact on military effectiveness.

\section{Popular Support and Material Resources}

Jenna Jordan (2014) also argues that the level of popular support a group enjoys matters for group resilience. Popular support provides organizations with a stream of resources in the form of funding, information, and recruits; it allows for groups to maintain their legitimacy and their political and/or ideological relevance; and, it allows groups to act covertly. Given popular support, insurgencies are expected to be better able to rebound or even maintain activity after leadership decapitation by replenishing the group's ranks and coffers. Resources can also come from outside sources, whether a foreign government or non-state actor, or lootable resources. Groups with a steady stream of resources are expected to be better able to withstand leadership decapitation.

Popular support is also the primary path through which groups may find themselves stronger after their leader has been removed; however, this is expected to be relatively uncommon. A number of studies argue that groups may retaliate against their foe following targeted killings (Gill et al., 2016; Jordan, 
2009; Mannes, 2008), such as Hezbollah's increase of suicide attacks on Israel following attacks on its leaders in the 1980s (Byman, 2006). An increase in attacks does not necessarily denote an increase in military capacity, however. Abrahms and Mierau (2015) and Abrahms and Potter (2015) argue that removing top leaders has the effect of promoting lower-level managers, who are likely to be less restrained in attacking civilians. Both studies find that leadership decapitation increases indiscriminate attacks against civilians. At the same time, they find that removing top leaders leads to a decrease in the number or proportion of attacks against militarily targets, suggesting that these targeted killings degrade the group militarily despite more attacks against civilians.

Groups may actually become militarily stronger in the case that leadership decapitation creates martyrs and generates publicity for the organization (Byman, 2006; Cronin, 2011; Hunter, 2009; Kaplan et al., 2005). The publicity gained as a result of targeted killings can signal the group's resolve, legitimize their use of violence among the population, and aid in recruitment, ultimately fortifying the organization. As noted by Johnston (2012), though, this is only likely to happen if the leader is popular and the group and larger population wants him to remain in power. Thus while strengthening is possible, it is contingent on the group's ability to withstand the removal of the leader and popular support.

\section{Expectations}

On average, leadership decapitation is expected to militarily weaken rebel groups in the short term. Leaders are particularly important to insurgencies, while centralized, non-bureaucratized, and resourcepoor organizations are particularly susceptible to degradation following leadership removal. As a result, leadership decapitation is expected to increase the likelihood of civil war termination, and in particular, produce outcomes favorable to the government given that the group is weakened to the point of being ineffective. Favorable outcomes are conceptualized here as either a government victory or a war that ends due to inactivity (Fortna, 2015). Government victory is certainly the best outcome for the government, as they achieve victory, see the rebel group dismantled, and avoid making any political concessions. A low activity outcome, in which the rebellion dies out but is not necessarily defeated, is also positive for the government. No policy concessions are given and the immediate threat ends.

Hypothesis 1. Leadership decapitation increases the likelihood of civil war termination.

Hypothesis 2. Leadership decapitation increases the likelihood of favorable outcomes for the government, including government victory and low activity outcomes. 
Beyond these short-term effects, it is also important to examine the long-term impact of leadership decapitation. Here, the effect of decapitation on civil war recurrence is considered. Existing research finds that the status of a rebel group at the end of the war matters for recurrence (Licklider, 1995; Toft, 2010; Wagner, 1993). In particular, military victory tends to produce lasting peace in comparison to negotiated settlements, as victories lead to the dismantling or destruction of the rebel organization, making it difficult for the insurgents to regroup and militarily engage the government (Licklider, 1995). In addition to degrading the opposition to the point that insurgents abandon the conflict, following victory "a great deal of immediate legitimacy attaches to winners, enhancing their position in the transition from war to peace" (Toft, 2010, 28). Victory brings together both the degradation of the rebel group as well as legitimacy in the victory, making recurrence less likely. While the underlying grievances may be present, in general groups are unable and perhaps no longer willing to reignite the conflict following defeat.

Based on these arguments from the civil war recurrence literature, it is expected that decapitation will have little overall effect on the chances of recurrence absent military defeat. Removing a group's leader alone may degrade the group militarily, but is unlikely to destroy the group outright. Reemergence will depend on the group's ability to subsist long enough to find a replacement leader and rebuild the organization. This is about the ability of the group to procure weapons and fighters, as well as its ability to effectively sell its political message. While it is possible that groups will cease to exist absent their leader, especially if the leader occupied an important ideological role, there are few reasons to believe that decapitation will be a long-term strategy if the organization itself is not defeated. Underlying incompatibilities will not be resolved, the networks and infrastructure for rebellion may be in place (Daly, 2016), and the group may feel particularly motivated to avenge the death of their leader. Following conflict termination, groups without a leader may be in a worse position in comparison to insurgencies that retained their top commander; however, this is not expected to be enough of a disadvantage to significantly reduce the risk of recurrence.

Indeed, arguments that leadership removal make groups stronger are often applicable in the long-term. The Islamic State fits within this mold. In 2010, the top leaders of the then-Islamic State in Iraq (ISI), Abu Ayuab al-Masri and Abu Umar Abdullah al-Rashid al-Bahghdadi, were killed in a joint US-Iraqi raid, and within two months 34 of the group's 42 leaders had been killed or captured (Hashim, 2014). This weakened the group in the short-term, as expected; however, removing the top leaders set the stage for the emergence of Abu Bakr al-Baghdadi, who significantly reorganized the ISI and clearly articulated the 
group's goals (Hashim, 2014). Coupled with the internal problems within the Iraqi state and outbreak of the Syrian civil war, the modern Islamic State emerged.

Hypothesis 3. All else equal, leadership decapitation has no effect on recurrence.

The combination of military defeat and the removal of a group's leader, on the other hand, is expected to have lasting effects. In this case the benefits of victory are realized. The insurgency is expected to be largely destroyed and leaderless, while the government enjoys the legitimacy of a military victory. This is expected to make it particularly difficult for an insurgency to mount the resources and personnel needed to relaunch the conflict. Sri Lanka's victories over both the Janatha Vimukthi Peramuna (JVP) and Liberation Tigers of Tamil Eelam (LTTE) provide examples. In both cases, victory was obtained following the government's significant gains made against the group, including the killing of high level operatives as well as Wijeweera and Prabhakaran, the top leaders and founders of the JVP and LTTE, respectively (Hill, 2013; Swamy, 2010).

Hypothesis 4. Leadership decapitation decreases the chances of civil war recurrence if the war ends in a military victory.

\section{Research Design}

To test expectations on the role of leadership decapitation, a series of tests are conducted on civil war termination and civil war recurrence. The UCDP Dyadic Dataset is used to identify the population of civil conflicts from 1989 to 2014 (Harbom et al., 2008). An armed conflict is included in Dyadic Dataset if it produces a minimum of 25 battle-related deaths in a given year and is fought between a government and internal, organized opposition group. The dyadic data are used to capture the effect of rebel leader removal, which is measured at the group (rather than conflict) level.

\section{Dependent Variables}

\section{Conflict Termination}

For models on civil war termination, the dependent variable is the time in years to termination. Conflict termination is defined two ways: a termination is coded if there is 1) at least a one-year break in the fighting (i.e., no conflict recorded by the Armed Conflict Dataset), and 2) at least a three-year period of non-conflict. The one-year break allows for a test of the immediate effect of decapitation and is considered to be a more generous test for termination. The three-year break allows for a clearer separation of conflict periods from one another, and increases certainty in the conflict termination 
dates. The use of a three-year break is common in the civil war termination literature (Cunningham, 2006; Wood and Kathman, 2014), and is expected to be a harder test for termination.

I first test the effect of decapitation on the time to termination using a Cox proportional hazard model. Cox models are semiparametric in that they do not specify functional form for the underlying hazard, but they do assume that the effect of the covariates are proportional. I then test the effect of decapitation on different termination types using a competing risks hazard model. Civil wars can end in four different ways, including government victory, rebel victory, negotiated settlements, and termination through low activity, data for which are taken from the UCDP Conflict Termination Dataset (Kreutz, 2010). Correspondingly, independent variables can have different effects on the hazard (the likelihood a civil war will end at one point in time, given that it has survived until that point) of observing a given type of termination. A competing risks model allows for different types of conflict terminations to be taken into consideration by treating the various outcomes as competing events, as only one of them can occur first. Competing risks models are also semiparametric and assume proportional hazards. Models were estimated using competing risks regression based on the methods of Fine and Gray (1999). For both the Cox and competing risks models, tests of the proportional hazards assumption were conducted. ${ }^{4}$ Robust standard errors are clustered at the conflict-dyad.

\section{Conflict Recurrence}

The second set of models tests civil war recurrence, where the dependent variable is the time in years from conflict termination until conflict resumes. In this case, recurrence is defined as renewed conflict between the same government and rebel group. Conflict termination is again defined in two ways: a conflict is coded as terminated if 1 ) there is at least one year of peace, and 2) there are at least three years of peace. The one-year break is expected to be a harder test for the effect of decapitation, as it will capture relatively short breaks in the fighting. Cox models are used for these analyses, with robust standard errors clustered at the conflict-dyad.

\section{Independent Variables}

The independent variable of interest is rebel leader decapitation. This is defined as the purposeful killing or capturing of a rebel group's top leader. The measure is based on work by Tiernay (2015) and supplemented with data from Johnston (2012). Additional cases of decapitation were collected to update the measure through 2014. In collecting these data, I used information from a variety of sources, including Keesing's Contemporary Archives, Lexis-Nexis, and UCDP's Conflict Encyclopedia. There are a total of 54 leadership decapitations in the period from 1989-2014. 
For the termination models, this variable is coded as 1 in the year that a successful leadership decapitation occurs as well as 1 in the year after a leader is removed. This is done to account for immediate effects of decapitation as well as a lagged effect. Additional tests are also conducted to examine different time effects, and results are included in Appendix Tables A1-A4. ${ }^{5}$ For the models of recurrence, a variable for leadership decapitation is coded as 1 if there was a successful leadership removal in either the last or second-to-last year of the conflict.

In addition to the main independent variable, a series of additional independent variables are also included. Measures of rebel capacity are taken from the Non-State Actor Dataset (Cunningham et al., 2009), including a measure of rebel group strength, relative to the government, and an indicator of rebel territorial control. Group strength is coded as 0 if the rebel group is much weaker than the government, 1 if the group is weaker than the government, and 2 if the rebel group is either at parity or stronger than the government. ${ }^{6}$ Territorial control is a binary indicator for whether a rebel group has a moderate level of control over territory.

Measures related to the government include regime type and military size. The widely-used Polity scale is used to measure regime type, which ranges from -10 to 10 (Marshall and Jaggers, 2006), while the logged number of military personnel per 1,000 people is taken from the Military Balance data (gathered using the World Bank Development Indicators interface). ${ }^{7}$

The logged severity of the conflict is included, which is taken from the UCDP Battle-Related Deaths Dataset (Melander et al., 2016). Indicators for whether the war is a conflict over territorial secession is also included, as well as the number of active conflict dyads in a given country. Both measures were constructed using the ACD. Finally, a measure of population size (logged), taken from the World Bank's World Development Indicators, is included as a control variable.

In the models for civil war recurrence only, the duration of the conflict, in logged years, is included, as well as indicators for how the war ended. Low activity is coded as 1 if the war ended via low activity, and government victory is coded as 1 if the war ended via government victory. These two variables are also further broken down to capture the effect of decapitation on conflict outcome. Variables for government victories with and without decapitation, as well as low activity outcomes with and without decapitation, are also tested. ${ }^{8}$ 


\section{Results}

Results for civil war termination can be found in Tables 1 and 2, which test the effect of decapitation on termination. Termination is defined as a one-year break in the fighting for Table 1, and three-year break in Table 2. Hazard ratios are displayed. A value over 1 indicates that the conflict is more likely to end given that it has survived up to that point, while a value less than 1 indicates it is less likely to end.

Results are generally supportive of expectations. When looking across all conflicts, civil wars are more likely to end if a leader is removed. The indicator for leadership decapitation in Model 1, which includes all termination types, violates the proportional hazard assumption, and as a result an interaction effect between leadership decapitation and the log of time is included. The combined coefficient for both the main effect and its interaction with time can be seen in Figure $1 .{ }^{9}$ Results suggest that decapitation always increases the likelihood of termination, the effect becomes stronger over time, and is statistically significant after the first year of conflict. After 5 years, conflicts are about 2.2 times more likely to end after leadership decapitation, which grows to 2.7 times more likely after 10 years.

Table 1. Duration Models of the Effect of Leadership Decapitation on War Termination, One-Year Break

\begin{tabular}{lccccc}
\hline & $1:$ & $2:$ & $3:$ & $4:$ & $5:$ \\
& All Conflicts & Gov't Victory & Low Activity & $\begin{array}{c}\text { Settlements } \\
\text { Rebel Victory }\end{array}$ \\
\hline \hline Decapitation & 1.129 & 1.417 & $2.151^{* *}$ & 1.532 & $0.000^{* * *}$ \\
& $(0.590)$ & $(0.654)$ & $(0.007)$ & $(0.314)$ & $(0.000)$ \\
Decapitation * time & $1.526^{*}$ & - & - & - & - \\
& $(0.012)$ & & & & \\
Rebel Strength & $1.167 \dagger$ & 0.861 & $0.534^{* *}$ & $1.400 \dagger$ & $3.30{ }^{+}$ \\
& $(0.089)$ & $(0.666)$ & $(0.004)$ & $(0.089)$ & $(0.059)$ \\
Rebel Strength * time & - & - & - & $1.217^{*}$ & - \\
& & & & $(0.041)$ & \\
Territorial Control & 0.885 & 1.150 & 0.714 & $1.927^{* *}$ & 0.669 \\
& $(0.262)$ & $(0.728)$ & $(0.135)$ & $(0.003)$ & $(0.463)$ \\
Gov't Military Size & 0.633 & 0.782 & 1.096 & 0.957 & 0.970 \\
& $(0.566)$ & $(0.257)$ & $(0.373)$ & $(0.666)$ & $(0.910)$ \\
Regime Type & 0.997 & 0.993 & $0.970^{*}$ & $1.075^{* * *}$ & 1.008 \\
& $(0.744)$ & $(0.838)$ & $(0.028)$ & $(0.000)$ & $(0.899)$ \\
Severity (log) & $0.751^{* * *}$ & 0.936 & $0.677^{* * *}$ & 0.920 & $1.668^{*}$ \\
& $(0.000)$ & $(0.687)$ & $(0.000)$ & $(0.290)$ & $(0.021)$ \\
Secession & $1.332 \dagger$ & 0.836 & 1.189 & 0.993 & 0.317 \\
& $(0.054)$ & $(0.662)$ & $(0.442)$ & $(0.975)$ & $(0.156)$ \\
Secession * time & 0.820 & - & - & - & -
\end{tabular}




\begin{tabular}{|c|c|c|c|c|c|}
\hline Active Dyads & $\begin{array}{l}1.078 * \\
(0.025)\end{array}$ & $\begin{array}{l}0.856^{*} \\
(0.225)\end{array}$ & $\begin{array}{c}0.986 \\
(0.788)\end{array}$ & $\begin{array}{c}1.021 \\
(0.761)\end{array}$ & $\begin{array}{c}0.896 \\
(0.635)\end{array}$ \\
\hline Active Dyads * time & - & $\begin{array}{l}0.543^{*} \\
(0.038)\end{array}$ & - & - & $\begin{array}{c}1.342^{* *} \\
(0.005)\end{array}$ \\
\hline Population (log) & $\begin{array}{l}0.991 \dagger \\
(0.081)\end{array}$ & $\begin{array}{c}1.053 \\
(0.768)\end{array}$ & $\begin{array}{c}1.056 \\
(0.427)\end{array}$ & $\begin{array}{l}0.873 \dagger \\
(0.098)\end{array}$ & $\begin{array}{c}0.800 \\
(0.361)\end{array}$ \\
\hline Population * time & $\begin{array}{c}0.941 \\
(0.202)\end{array}$ & - & - & - & - \\
\hline$N$ & 1,107 & 1,107 & 1,107 & 1,107 & 1,107 \\
\hline$N_{\text {Conflicts }}\left(N_{\text {Terminations }}\right)$ & $350(323)$ & $350(29)$ & $350(143)$ & $350(108)$ & $350(16)$ \\
\hline$\chi^{2}$ & $77.93 * * *$ & 14.280 & $78.852 * * *$ & $54.91 * * *$ & $1334.291 * * *$ \\
\hline Log-Likelihood & -1612.717 & -162.278 & -759.597 & -584.861 & -75.387 \\
\hline
\end{tabular}

Table 2. Duration Models of the Effect of Leadership Decapitation on War Termination, Three-Year Break

\begin{tabular}{|c|c|c|c|c|c|}
\hline & $\begin{array}{c}\text { 6: } \\
\text { All Conflicts }\end{array}$ & $\begin{array}{c}7: \\
\text { Gov't Victory }\end{array}$ & $\begin{array}{c}\text { 8: } \\
\text { Low Activity }\end{array}$ & $\begin{array}{c}\text { 9: } \\
\text { Settlements }\end{array}$ & $\begin{array}{c}\text { 10: } \\
\text { Rebel Victory }\end{array}$ \\
\hline Decapitation & $\begin{array}{c}0.972 \\
(0.925)\end{array}$ & $\begin{array}{c}1.090 \\
(0.896)\end{array}$ & $\begin{array}{l}1.815^{\dagger} \\
(0.063)\end{array}$ & $\begin{array}{c}1.615 \\
(0.259)\end{array}$ & $\begin{array}{c}0.000^{* * *} \\
(0.000)\end{array}$ \\
\hline Decapitation * time & $\begin{array}{c}1.769 * * \\
(0.005)\end{array}$ & - & - & - & - \\
\hline Rebel Strength & $\begin{array}{l}1.2256^{*} \\
(0.028)\end{array}$ & $\begin{array}{c}0.823 \\
(0.557)\end{array}$ & $\begin{array}{l}0.983^{*} \\
(0.958)\end{array}$ & $\begin{array}{l}1.668^{* *} \\
(0.009)\end{array}$ & $\begin{array}{l}3.068^{\dagger} \\
(0.059)\end{array}$ \\
\hline Rebel Strength * time & - & - & $\begin{array}{c}0.506 * * \\
(0.002)\end{array}$ & - & - \\
\hline Territorial Control & $\begin{array}{c}0.951 \\
(0.702)\end{array}$ & $\begin{array}{c}1.204 \\
(0.651)\end{array}$ & $\begin{array}{c}0.665 \\
(0.116)\end{array}$ & $\begin{array}{c}2.089 * * \\
(0.003)\end{array}$ & $\begin{array}{c}0.641 \\
(0.413)\end{array}$ \\
\hline Gov't Military Size & $\begin{array}{c}0.999 \\
(0.993)\end{array}$ & $\begin{array}{c}0.775 \\
(0.207)\end{array}$ & $\begin{array}{c}1.128 \\
(0.304)\end{array}$ & $\begin{array}{c}0.935 \\
(0.549)\end{array}$ & $\begin{array}{c}0.955 \\
(0.860)\end{array}$ \\
\hline Regime Type & $\begin{array}{l}1.030^{*} \\
(0.037)\end{array}$ & $\begin{array}{c}0.991 \\
(0.789)\end{array}$ & $\begin{array}{l}1.016^{*} \\
(0.537)\end{array}$ & $\begin{array}{c}1.081 * * * \\
(0.000)\end{array}$ & $\begin{array}{l}1.008 \\
(0.895)\end{array}$ \\
\hline Regime Type * time & $\begin{array}{c}0.974 * * \\
(0.007)\end{array}$ & - & $\begin{array}{c}0.943^{* *} \\
(0.006)\end{array}$ & - & - \\
\hline Severity (log) & $\begin{array}{l}0.858^{*} \\
(0.013)\end{array}$ & $\begin{array}{c}0.729 \\
(0.104)\end{array}$ & $\begin{array}{c}0.646 * * * \\
(0.000)\end{array}$ & $\begin{array}{l}0.867 \dagger \\
(0.080)\end{array}$ & $\begin{array}{l}1.631^{*} \\
(0.024)\end{array}$ \\
\hline Severity * time & $\begin{array}{c}0.912 * * \\
(0.010)\end{array}$ & $\begin{array}{c}1.357^{* * *} \\
(0.008)\end{array}$ & - & - & - \\
\hline Secession & $\begin{array}{c}0.911 \\
(0.516)\end{array}$ & $\begin{array}{c}0.894 \\
(0.782)\end{array}$ & $\begin{array}{c}1.249 \\
(0.392)\end{array}$ & $\begin{array}{c}0.876 \\
(0.616)\end{array}$ & $\begin{array}{c}0.354 \\
(0.192)\end{array}$ \\
\hline Active Dyads & $\begin{array}{l}1.085^{*} \\
(0.025)\end{array}$ & $\begin{array}{c}0.834 \\
(0.207)\end{array}$ & $\begin{array}{c}1.002 \\
(0.977)\end{array}$ & $\begin{array}{c}1.013 \\
(0.867)\end{array}$ & $\begin{array}{c}0.882 \\
(0.580)\end{array}$ \\
\hline Active Dyads * time & - & $\begin{array}{l}0.645^{*} \\
(0.042)\end{array}$ & - & - & $\begin{array}{c}1.330 * * \\
(0.005)\end{array}$ \\
\hline Population (log) & $\begin{array}{c}0.874 * * \\
(0.006)\end{array}$ & $\begin{array}{c}1.050 \\
(0.767)\end{array}$ & $\begin{array}{c}1.016 \\
(0.854)\end{array}$ & $\begin{array}{c}0.907 \\
(0.288)\end{array}$ & $\begin{array}{c}0.826 \\
(0.405)\end{array}$ \\
\hline
\end{tabular}




\begin{tabular}{|c|c|c|c|c|c|}
\hline$N$ & 1,194 & 1,194 & 1,194 & 1,194 & 1,194 \\
\hline$N_{\text {Conflicts }}\left(N_{\text {Terminations }}\right)$ & $280(294)$ & $280(28)$ & $280(92)$ & $280(87)$ & $280(16)$ \\
\hline$\chi^{2}$ & $50.882 * * *$ & $20.470^{*}$ & $62.060 * * *$ & $37.724 * * *$ & $824.530 * * *$ \\
\hline Log-Likelihood & -1214.029 & -147.211 & -460.390 & -451.635 & -72.654 \\
\hline
\end{tabular}

Cox hazard ratios displayed for Model 1; competing risks regression hazard ratios displayed for Models 2-5

p-values listed in parentheses. ${ }^{* * *} p<0.001,{ }^{* *} p<0.01,{ }^{*} p<0.05,+p<0.10$

When different termination types are considered, wars that end in low activity are about 2.2 times more likely to end following leadership decapitation, which is statistically significant. There are also no cases of rebel victory if a leader is decapitated, but given the relative rarity of rebel victories, this result should be viewed with greater caution as it may be an artifact of the available data. Taken together, these results lend support to the hypothesis that decapitation militarily degrades rebel groups, making it more difficult for insurgencies to win outright. The effect of decapitation is also in the expected direction for government victories, but this finding is not statistically significant. Perhaps even more problematic, the model as a whole is insignificant. Given the high levels of recurrence for low activity outcomes and the null findings for government victories, these results paint a less optimistic picture regarding the overall effectiveness of leadership removal.

Turning to a three-year break, which is expected to be a more difficult test for the effect of decapitation, the results are largely in line when termination is defined as only a one-year break. Across all termination types, leadership decapitation again violates the proportional hazard assumption, but results are in line with the one-year break findings. After 5 years, wars are about 2.7 times more likely to end following decapitation, and about 3.0 times more likely to end after 10 years. Decapitation increases the chances of low activity outcomes by about 1.9 times, and there continue to be no cases of rebel group following decapitation.
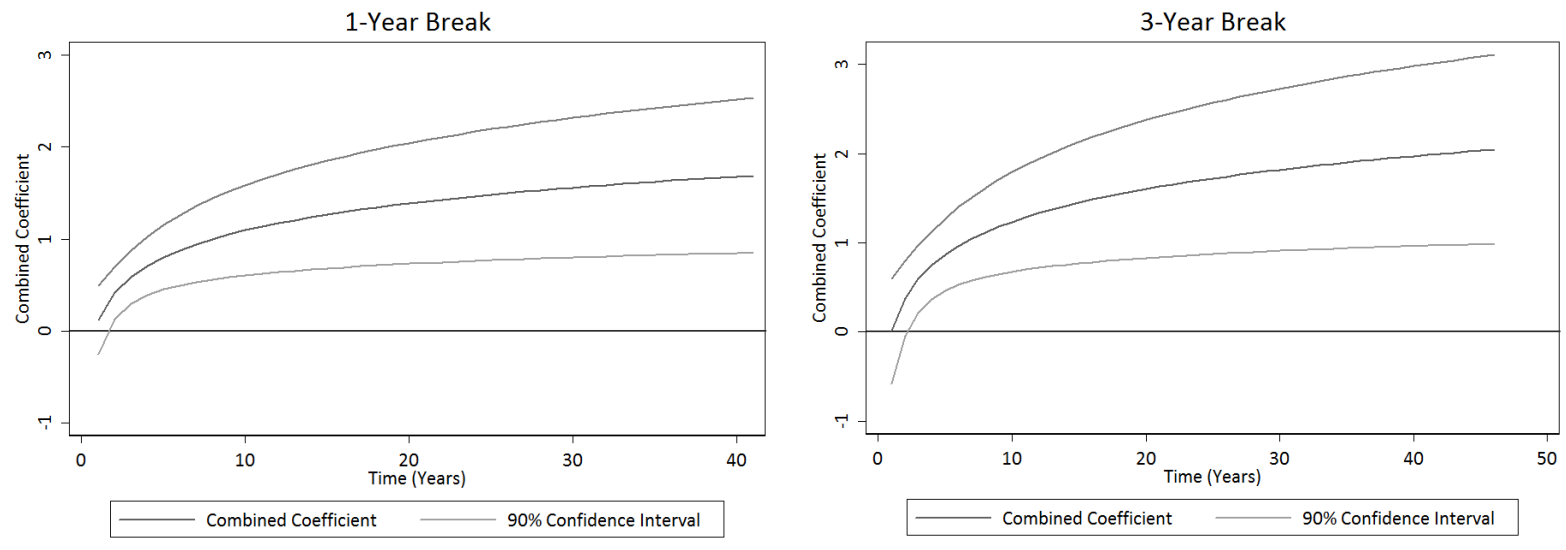
Figure 1. Combined Coefficient Plots for Leadership Decapitation in All Conflicts

For the control variables, government victories appear difficult to predict. Governments are significantly less likely to win conflicts when they are fighting against more than one rebel group; however, there are no additional statistically significant findings. Low activity outcomes are more likely to occur against weak rebel groups, in more authoritarian states, and for low severity conflicts. Settlements are more likely against strong rebels with territorial control, and within more democratic states. Rebel victories are also more likely to occur if the rebel group is strong relative to the government, and these outcomes also tend to come after high-intensity conflicts.

To further delve into the results on the effect of decapitation, and test the underlying mechanisms discussed earlier, additional tests were conducted on what makes decapitation more likely to be successful. Success is defined as a war that ended in the same year or the year following the removal of a rebel group leader. There are a total of 54 cases of leadership decapitation, and 30 are considered "successful" in that the war ended in that year or the following year. A number of independent variables, drawn from the discussion of the role of leaders, organizational structure, and resources, were tested to examine the determinants of success. Figure 2 displays coefficient plots for the models that were significant overall, with full results are available in Appendix Table A11.

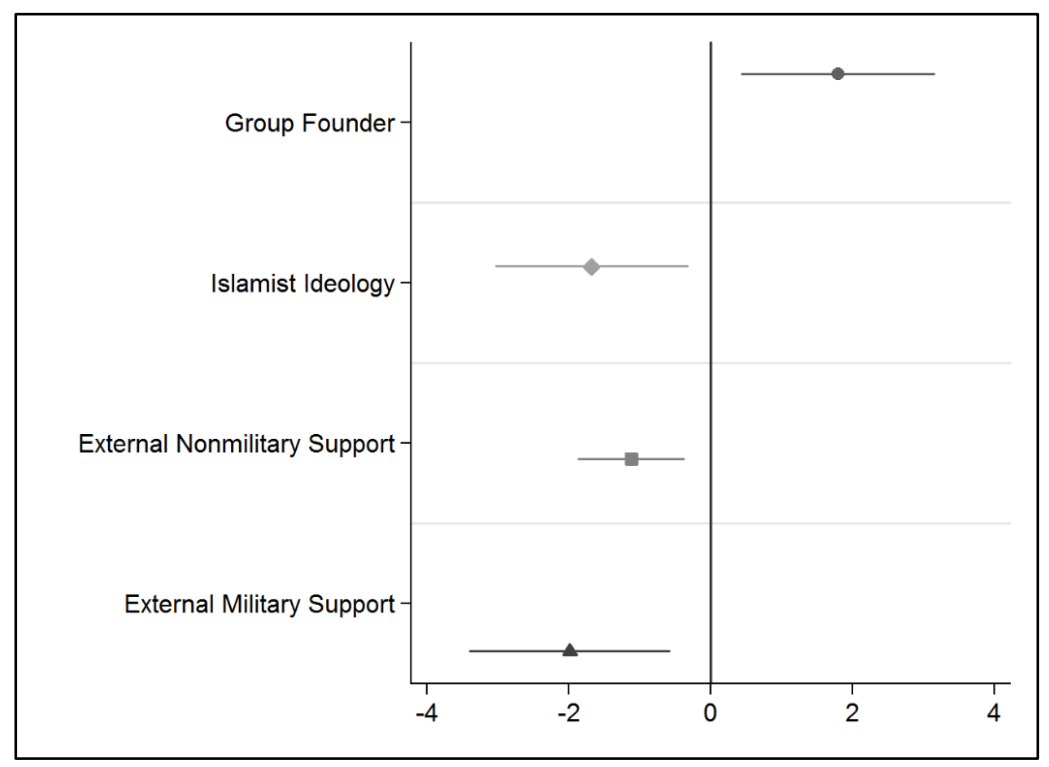

Figure 2. Coefficient Plot of the Determinants of Successful Decapitation Attempts

First, a measure of whether the group founder was removed was tested. This is expected to proxy the relative importance of a leader to the group's ideological and operational missions. Decapitation 
attempts that successfully remove a group's founder are about twice as likely to be successful. A number of indicators measuring an insurgency's organizational structure were tested (each taken from the NSAD), but none were statistically significant, including whether the group has central control, strength of the central control, group size, and whether there is a political wing. Popular support was measured using a group's mobilization capacity, but was not significant, while groups with an Islamist ideology are less vulnerable to decapitation. It is difficult to pinpoint what the Islamist measure is capturing - it may tap into popular support, perceived ideological legitimacy, or capture another dimension of groups that tend to have an Islamist ideology. Finally, decapitation is significantly less likely to be successful if the group has external support, whether it is military or nonmilitary in nature. This suggests that removing group founders, Islamist ideology, and external support are particularly important in understanding when decapitation is likely to be successful.

Table 3. Duration Models of the Effect of Leadership Decapitation on War Recurrence, One-Year Break

\begin{tabular}{lccc}
\hline & $1:$ & $2:$ & $3:$ \\
& All Conflicts & All Conflicts & All Conflicts \\
\hline \hline Decapitation & 0.801 & 0.647 & - \\
Gov't Victory & $(0.556)$ & $(0.238)$ & \\
Gov't Victory + Decapitation & - & 0.754 & - \\
& - & $(0.471)$ & \\
Gov't Victory, No Decapitation & - & - & $0.000^{* * *}$ \\
& & & $(0.000)$ \\
Low Activity & - & $2.143^{* * *}$ & 0.841 \\
& & $(0.000)$ & - \\
Low Activity + Decapitation & - & - & 1.467 \\
& & & $(0.344)$ \\
Low Activity, No Decapitation & - & - & $2.177^{* * *}$ \\
& & & $(0.000)$ \\
Secession & $2.181^{* *}$ & $2.054 * *$ & $2.086^{* * *}$ \\
Severity (log) & $(0.001)$ & $(0.001)$ & $(0.001)$ \\
& $0.876 \dagger$ & 0.945 & 0.947 \\
Duration (log) & $(0.054)$ & $(0.416)$ & $(0.442)$ \\
& $1.741^{* * *}$ & $1.640 * * *$ & $1.645^{* * *}$ \\
Population (log) & $(0.000)$ & $(0.000)$ & $(0.000)$ \\
Regime Type & 1.089 & 1.050 & 1.0447 \\
& $(0.193)$ & $(0.430)$ & $(0.442)$ \\
& 0.996 & 1.008 & 1.001 \\
& $(0.755)$ & $(0.596)$ & $(0.582)$ \\
& & &
\end{tabular}




\begin{tabular}{lccc} 
Active Dyads & 0.940 & 0.940 & 0.939 \\
& $(0.229)$ & $(0.206)$ & $(0.204)$ \\
\hline$N$ & 3,451 & 3,451 & 3,451 \\
$N_{\text {Conflicts }}\left(N_{\text {Terminations }}\right)$ & $357(130)$ & $357(130)$ & $357(130)$ \\
$\chi^{2}$ & $96.674 * * *$ & $120.767 * * *$ & $119.23 * * *$ \\
Log-Likelihood & -699.500 & -690.586 & -690.005 \\
\hline Cox hazard ratios with $p$-values listed in parentheses. ${ }^{* * *} p<0.001,{ }^{* *} p<0.01,{ }^{*} p<0.05,+p<0.10$
\end{tabular}

Moving to the models for of civil war recurrence, presented in Tables 3 and 4, results generally meet expectations. In Models 1 and 4, which both test the effect of decapitation without taking war outcome into account, the effect is not statistically significant and actually switches direction depending if termination is defined as a one or three year break in fighting. This suggests that decapitation has very little impact on the chances of recurrence, making it neither more nor less likely to occur. Once conflict outcomes are included, shown in Models 2 and 5, decapitation appears to make recurrence less likely; however, neither result is statistically significant.

Table 4. Duration Models of the Effect of Leadership Decapitation on War Recurrence, Three-Year Break

\begin{tabular}{|c|c|c|c|}
\hline & $\begin{array}{c}4: \\
\text { All Conflicts }\end{array}$ & $\begin{array}{c}5: \\
\text { All Conflicts }\end{array}$ & $\begin{array}{c}6: \\
\text { All Conflicts }\end{array}$ \\
\hline Decapitation & $\begin{array}{c}1.247 \\
(0.650)\end{array}$ & $\begin{array}{c}0.954 \\
(0.926)\end{array}$ & - \\
\hline Gov't Victory & - & $\begin{array}{l}1.085 \\
(0.877)\end{array}$ & - \\
\hline Gov't Victory + Decapitation & - & - & $\begin{array}{c}0.000 * * * \\
(0.000)\end{array}$ \\
\hline Gov't Victory, No Decapitation & - & - & $\begin{array}{c}1.198 \\
(0.732)\end{array}$ \\
\hline Low Activity & - & $\begin{array}{l}2.214^{*} \\
(0.035)\end{array}$ & - \\
\hline Low Activity + Decapitation & - & - & $\begin{array}{c}2.043 \\
(0.222)\end{array}$ \\
\hline Low Activity, No Decapitation & - & - & $\begin{array}{l}2.277^{*} \\
(0.032)\end{array}$ \\
\hline Secession & $\begin{array}{c}3.392^{* * *} \\
(0.000)\end{array}$ & $\begin{array}{c}3.170 * * * \\
(0.000)\end{array}$ & $\begin{array}{c}3.198^{* * *} \\
(0.000)\end{array}$ \\
\hline Severity (log) & $\begin{array}{c}0.854 \\
(0.117)\end{array}$ & $\begin{array}{c}0.933 \\
(0.534)\end{array}$ & $\begin{array}{c}0.945 \\
(0.631)\end{array}$ \\
\hline Duration (log) & $\begin{array}{c}1.264 \\
(0.142)\end{array}$ & $\begin{array}{c}1.213 \\
(0.292)\end{array}$ & $\begin{array}{c}1.217 \\
(0.283)\end{array}$ \\
\hline Population (log) & 1.030 & 0.997 & 0.993 \\
\hline
\end{tabular}




\begin{tabular}{lccc} 
& $(0.762)$ & $(0.979)$ & $(0.945)$ \\
Regime Type & 0.986 & 0.997 & 0.999 \\
& $(0.544)$ & $(0.911)$ & $(0.972)$ \\
Active Dyads & 0.949 & 0.938 & 0.936 \\
& $(0.538)$ & $(0.493)$ & $(0.486)$ \\
\hline$N$ & 3,345 & 3,345 & 3,345 \\
$N_{\text {Conflicts }}\left(N_{\text {Terminations }}\right)$ & $276(49)$ & $276(49)$ & $276(49)$ \\
$\chi^{2}$ & $28.585^{* * *}$ & $33.415^{* * *}$ & $32.61 * * *$ \\
Log-Likelihood & -250.830 & -247.901 & -247.481 \\
\hline Cox hazard ratios with $p$-values listed in parentheses. ${ }^{* * *} p<0.001,{ }^{* *} p<0.01,{ }^{*} \mathrm{p}<0.05,+p<0.10$
\end{tabular}

For war outcomes, government victory is surprisingly not statistically significant in either specification. In Model 2, government victory is in the predicted direction, decreasing the likelihood of recurrence. In Model 5, however, it appears to make recurrence more likely, although the effect is likely due to chance. Low activity outcomes, by contrast, increase the chances of recurrence, which is statistically significant across models. Wars that end because the death toll falls below the 25 -death threshold are over twice as likely to recur for both specifications.

In the final set of tests, Models 3 and 6 include war outcomes that are conditioned by whether there was a successful removal of the rebel group's leader, either in the last or second-to-last year of the conflict. For government victories, there are no cases of recurrence if there was also leader decapitation. This is supportive of the expectation that decapitation will be particularly effective if the government wins the conflict, as the rebel group is likely to be dismantled without a clear path forward to regroup and resume the fight. Government victories without decapitation do not have a statistically significant impact on the chances of recurrence. Findings for low activity outcomes suggest that these conflicts are likely to recur; however, these findings are only statistically significant for low activity outcomes that did not have a successful decapitation attempt. If there was leadership decapitation in the final years of the conflict, it is no longer statistically more likely to recur. This is one of the few signs that decapitation may have a dampening effect on conflict recurrence for wars that do not end in military victory.

For the control variables, wars of secession are significantly more likely to recur, both in terms of statistical significance and magnitude. These conflicts appear to be particularly intractable, and are about 2 to 3 times more likely to start again after a break in fighting. If termination is defined as a minimum of one-year break in the fighting, duration increases the chances of recurrence by about 1.7 times. This may reflect a greater likelihood for long conflicts to have brief breaks in fighting, leading to a 
greater likelihood for the conflict to restart. This effect becomes insignificant for the three-year specification. None of the additional variables reach conventional levels of statistical significance.

\section{Extension of the Results: Killed versus Captured}

An important debate within the leadership decapitation literature surrounds the relative benefits of killing versus capturing group leaders. Some argue that arresting leaders can be more effective, due to fewer moral and legal issues, the ability to obtain information, and the demonstration that the rule of law ultimately triumphs over terror tactics (Cronin, 2006, 2011; Hepworth, 2014; Price, 2012). Others argue that killing a leader acts as a deterrent to future leaders, disrupts operational flow, forces the group to spend resources on selecting a new leader, and may lead to the group channeling resources towards protecting its leadership (Ganor, 2006; Wilner, 2010). The data on rebel group leaders collected here indicates if leaders were killed or captured, allowing for analyses of civil war termination and recurrence taking into account how the leader was removed.

The main results from the paper are reproduced in Appendix Tables A5-A10, in which the leadership decapitation indicator is separated into two different variables. Nearly $75 \%$ of decapitation efforts (41) involved killing the top leader. The killed and captured indicators follow the same coding scheme as the decapitation measure used in the main analyses. For the models on conflict termination, the killed (captured) indicator records whether a rebel group leader was killed (captured) in the current or previous year. For the models on conflict recurrence, killed (captured) measure indicates that the rebel group leader was killed (captured) in the last or second-to-last year of the war.

Overall, there are no clear patterns that suggest that either killing or capturing rebel group leaders is a more effective method. Both capturing and killing a rebel group leader is significantly more likely to bring a war to its end, in terms of magnitude and statistical significance. This effect appears to be stronger for leaders who are killed, which suggests that killing a leader is more likely to bring a war to an end. ${ }^{10}$ However, an important caveat throughout this analysis is the relative infrequency of capturing leaders. Only 14 rebel group leaders were captured in the available data. There is less information available for this type of leadership removal and thus greater uncertainty surrounding the results. When civil war termination is broken into different outcome types, there are no clear patterns and some of the results appear to be driven by relatively rare events (for example, the combination of a government victory and a leader being captured), rather than true relationships. These results are presented and further explored in the Appendix. ${ }^{11}$ 
When examining the impact of killing or capturing a leader on civil war recurrence, the results are very similar to those presented in the main results. ${ }^{12}$ Neither killing nor capturing a rebel leader decreases the likelihood of civil war recurrence, while there are no cases of recurrence after a group leader has been killed or captured in conjunction with government victory. Finally, as with the main results, only conflicts that end in low activity without a leader being either killed or captured are more likely to recur.

\section{Conclusion}

There is considerable interest regarding the effectiveness of leadership decapitation, especially among terrorism scholars. The effect of leadership removal on terror groups is unresolved; however, findings from Johnston (2012) and Tiernay (2015) suggest that decapitation can be a successful strategy to bring civil conflicts to an end, and in a way that is beneficial to the government. The goal of this analysis was to further explore this relationship to examine not only the shot-term effects of decapitation on conflict termination, but also the longer-term effects of decapitation on conflict recurrence.

Leadership decapitation was first expected to degrade a group's military capacity in the short-term. Individual leaders tend to be critical to the functioning of insurgencies, while groups that are highly centralized, not bureaucratized, and lack a steady stream of resources are more likely to be susceptible to leadership removal. However, while groups may be vulnerable to the effects of decapitation in the short-term, absent a military victory, the group will have existing networks that can be called upon to regroup and rearm to address unresolved grievances. While a group could completely collapse without a leader, the underlying incompatibility will remain unresolved. As a result, it was expected that decapitation will not significantly decrease the chances of recurrence.

Results were generally supportive of these expectations. Decapitation significantly increases the chances of termination overall as well as the chances of low activity outcomes in particular; however, there is no effect on the likelihood of government victory. Thus while decapitation may increase the chances of termination in a generally favorable way to the government, it is not in the form of government victories. Moving to recurrence, results are also in line with expectations. Wars that end in decapitation are no less likely to recur; however, there are no cases of conflicts that recur that end with government victory and leader decapitation. For low activity outcomes, there does appear to be a dampening effect if a war also ended with a decapitation, which is the only potentially positive long-term effect of leadership removal that was found. 
These findings are in line with the work done by both Tiernay and Johnston, but suggest that a note of caution is needed. If decapitation occurs in conjunction with military victory, it seems to be a powerful way to dismantle a rebel group, such as in Sri Lanka's fight against the LTTE and JVP. However, absent a military victory, the insurgency may very well regroup and come back to fight another day. In that sense, decapitation is not a permanent or even particularly long-term strategy. For governments and international partners attempting to bring a conflict to an end, decapitation may provide a reprieve from the fighting, especially if the founder can be removed or a group does not have external funding. But in the post-war period, the degraded group should not be considered defeated. This period may instead be a productive time for the group to be monitored or otherwise pacified to prevent war from starting anew.

There are a number of ways in which this relationship can be further explored, such as a more in depth analysis of the effectiveness of killing versus capturing a rebel group leader. The effect of decapitation on the larger conflict space also poses a number of interesting questions, including whether decapitation leads to the fragmentation of rebel groups or the reshuffling of personnel from the decapitated group to another active organization. It also remains possible that decapitation will have a negative impact on conflict duration and termination; for example, the use of decapitation on a fragmented or decentralized movement may prolong wars. Such negative externalities are important to better understand so they may be avoided.

\footnotetext{
${ }^{1}$ This is not to suggest that coding civil war termination is without controversy (Sambanis, 2004), but that there has been considerable effort to conceptualize and operationalize the termination of civil conflicts as well as different outcome types.

${ }^{2}$ Following the work done by Zussman and Zussman (2006), Jordan (2009), Johnston (2012), and Tiernay (2015), a group's "top leader" is identified by relying on primary and secondary sources used in data collection processes. These individuals are often the group's founder and play a central role in directing the group at the highest level, and tend to direct individuals in the upper echelon of an organization and high-level managers. At least two sources must identify an individual as the top leader to be considered as such.

${ }^{3}$ Movement fragmentation, which considers the number of factions within a larger movement as opposed to only the central command structure, may also play an important role and provide a line of future inquiry (e.g., Cunningham, 2011).

${ }^{4}$ An interaction between the log of time and each covariate was independently tested for differential effects over time. If significant interactive effects were found, they were included in the main results.

${ }^{5}$ If rebel decapitation is included at time $t$ (without a lag), results for termination overall are similar in direction and significance. Low activity outcomes are in the same direction, but do not reach conventional levels of significance. This holds for both the one and three year break. If rebel decapitation is included with a lag (at $t-1$ ), results for a one-year break in fighting are similar in direction and magnitude to the results presented here. For a three-year break, low activity outcomes are in the same direction and magnitude, while overall termination is in the same direction but does not reach conventional levels of significance.
} 
${ }^{6}$ The original indicator provides information on groups that are stronger and much stronger than the government, but this included less than one percent of groups in the data, and so these categories were collapsed.

${ }^{7}$ Missing values of the military personnel were generated using linear interpolation, which was required for 12 dyad-years. Models were also run without using the interpolated data, and results were nearly identical. ${ }^{8}$ Descriptive statistics for civil war termination models and civil war recurrence models are available in the Appendix, in Tables A12 and A13.

${ }^{9}$ Combined coefficient plots were constructed using the "nonph_graph" command in Stata that was developed by Michael Tiernay and described in Tiernay (2015). This command implements recommendations made by Licht (2011) for the substantive interpretation of nonproportional hazards.

${ }^{10}$ See Tables A5 and A7 for full results, as well as Figures A2 and A3.

${ }^{11}$ See Tables $A 6$ and $A 8$ for full results.

${ }^{12}$ See Tables $A 9$ and $A 10$ for full results. 


\section{Works Cited}

Abrahms M and Mierau J (2015) Leadership matters: The effects of targeted killings on militant group tactics. Terrorism and Political Violence 0(0): 1-22.

Abrahms M and Potter PBK (2015) Explaining Terrorism: Leadership Deficits and Militant Group Tactics. International Organization 69(2): 311-342.

Byman D (2006) Do Targeted Killings Work Essay. Foreign Affairs 85: 95-112.

Calderón G, Robles G, Díaz-Cayeros A, et al. (2015) The Beheading of Criminal Organizations and the Dynamics of Violence in Mexico. Journal of Conflict Resolution 59(8): 1455-1485.

Carley KM, Lee J-S and Krackhardt D (2002) Destabilizing Networks. Connections 24(3): 79-92.

Carvin S (2012) The Trouble with Targeted Killing. Security Studies 21(3): 529-555.

Cronin AK (2006) How al-Qaida Ends: The Decline and Demise of Terrorist Groups. International Security 31(1): 7-48.

Cronin AK (2011) How Terrorism Ends: Understanding the Decline and Demise of Terrorist Campaigns. Princeton University Press.

Cunningham DE (2006) Veto Players and Civil War Duration. American Journal of Political Science 50(4): 875-892.

Cunningham DE, Gleditsch KS and Salehyan I (2009) It Takes Two A Dyadic Analysis of Civil War Duration and Outcome. Journal of Conflict Resolution 53(4): 570-597.

Cunningham KG (2011) Divide and Conquer or Divide and Concede: How Do States Respond to Internally Divided Separatists? American Political Science Review 105(02): 275-297.

D'Alessio SJ, Stolzenberg L and Dariano D (2014) Does Targeted Capture Reduce Terrorism? Studies in Conflict \& Terrorism 37(10): 881-894.

Daly SZ (2016) Organized Violence after Civil War: The Geography of Recruitment in Latin America. Cambridge University Press.

Findley MG and Young JK (2012) Terrorism and Civil War: A Spatial and Temporal Approach to a Conceptual Problem. Perspectives on Politics 10(02): 285-305.

Fine JP and Gray RJ (1999) A Proportional Hazards Model for the Subdistribution of a Competing Risk. Journal of the American Statistical Association 94(446): 496.

Fortna VP (2015) Do Terrorists Win? Rebels' Use of Terrorism and Civil War Outcomes. International Organization 69(03): 519-556.

Freeman M (2014) A Theory of Terrorist Leadership (and its Consequences for Leadership Targeting). Terrorism and Political Violence 26(4): 666-687. 
Ganor B (2006) The Counter-Terrorism Puzzle: A Guide for Decision Makers. 6th edition. New Brunswick u.a.: Routledge.

Gill P, Piazza JA and Horgan J (2016) Counterterrorism Killings and Provisional IRA Bombings, 1970-1998. Terrorism and Political Violence 28(3): 473-496.

Gleditsch NP, Wallensteen P, Eriksson M, et al. (2002) Armed Conflict 1946-2001: A New Dataset. Journal of Peace Research 39(5): 615-637.

Hafez MM and Hatfield JM (2006) Do Targeted Assassinations Work? A Multivariate Analysis of Israel's Controversial Tactic during Al-Aqsa Uprising. Studies in Conflict \& Terrorism 29(4): 359-382.

Harbom L, Melander E and Wallensteen P (2008) Dyadic Dimensions of Armed Conflict, 1946-2007. Journal of Peace Research 45(5): 697-710.

Hashim AS (2014) The Islamic State: From al-Qaeda Affiliate to Caliphate. Middle East Policy 21(4): 6983.

Hepworth DP (2014) Terrorist retaliation? An analysis of terrorist attacks following the targeted killing of top-tier al Qaeda leadership. Journal of Policing, Intelligence and Counter Terrorism 9(1): 1-18.

Hill THJ (2013) The Deception of Victory: The JVP in Sri Lanka and the Long-Term Dynamics of Rebel Reintegration. International Peacekeeping 20(3): 357-374.

Hunter TB (2009) Targeted Killing: Self-Defense, Preemption, and the War on Terrorism. Journal of Strategic Security 2(2): 1-52.

Johnston PB (2012) Does Decapitation Work? Assessing the Effectiveness of Leadership Targeting in Counterinsurgency Campaigns. International Security 36(4): 47-79.

Johnston PB and Sarbahi AK (2016) The Impact of US Drone Strikes on Terrorism in Pakistan. International Studies Quarterly 60(2): 203-219.

Jordan J (2009) When Heads Roll: Assessing the Effectiveness of Leadership Decapitation. Security Studies 18(4): 719-755.

Jordan Jenna (2014) Attacking the Leader, Missing the Mark. International Security 38(4): 7-38.

Jordan Javier (2014) The Effectiveness of the Drone Campaign against Al Qaeda Central: A Case Study. Journal of Strategic Studies 37(1): 4-29.

Kaplan EH, Mintz A, Mishal S, et al. (2005) What Happened to Suicide Bombings in Israel? Insights from a Terror Stock Model. ResearchGate 28(3): 225-235.

Kenney M, Coulthart S and Wright D (2016) Structure and Performance in a Violent Extremist Network: The Small-world Solution. Journal of Conflict Resolution: 0022002716631104. 
Kober A (2007) Targeted Killing during the Second Intifada: The Quest for Effectiveness. Journal of Conflict Studies 27(1). Available from:

https://journals.lib.unb.ca/index.php/JCS/article/view/8292 (accessed 20 January 2017).

Kreutz J (2010) How and when armed conflicts end: Introducing the UCDP Conflict Termination dataset. Journal of Peace Research 47(2): 243-250.

Licht AA (2011) Change Comes with Time: Substantive Interpretation of Nonproportional Hazards in Event History Analysis. Political Analysis 19(2): 227-243.

Licklider R (1995) The Consequences of Negotiated Settlements in Civil Wars, 1945-1993. The American Political Science Review 89(3): 681-690.

Mannes A (2008) Testing The Snake Head Strategy: Does Killing or Capturing its Leaders Reduce a Terrorist Group's Activity? ResearchGate 9(Spring): 40-49.

Marshall MG and Jaggers K (2006) Polity IV Project: Political Regime Characteristics and Transitions, 1800-2004: Dataset Users' Manual. In: Polity IV Project, Center for Global Policy School of Public Policy, George Mason University.

Melander E, Pettersson T and Themnér L (2016) Organized violence, 1989-2015. Journal of Peace Research.

Morehouse M (2014) It's Easier to Decapitate a Snake than It Is a Hydra: An Analysis of Colombia's Targeted Killing Program. Studies in Conflict \& Terrorism 37(7): 541-566.

Morehouse MA (2015) The Claws of the Bear: Russia's Targeted Killing Program. The Journal of Slavic Military Studies 28(2): 269-298.

Phillips BJ (2015) How Does Leadership Decapitation Affect Violence? The Case of Drug Trafficking Organizations in Mexico. The Journal of Politics 77(2): 324-336.

Price BC (2012) Targeting Top Terrorists: How Leadership Decapitation Contributes to Counterterrorism. International Security 36(4): 9-46.

Sambanis N (2004) What Is Civil War? Conceptual and Empirical Complexities of an Operational Definition. The Journal of Conflict Resolution 48(6): 814-858.

Shapiro JN (2013) The Terrorst's Dilemma: Managing Violent Covert Organizations. Princeton, NJ: Princeton University Press.

Stanton JA (2013) Terrorism in the Context of Civil War. The Journal of Politics 75(04): 1009-1022.

Swamy MRN (2010) The Tiger Vanquished: LTTE's Story. New Delhi, India: SAGE Publications India.

Tiernay M (2015) Killing Kony Leadership Change and Civil War Termination. Journal of Conflict Resolution 59(2): 175-206.

Toft MD (2010) Ending Civil Wars: A Case for Rebel Victory? International Security 34(4): 7-36. 
Uyangoda J (2010) Sri Lanka in 2009: From Civil War to Political Uncertainties. Asian Survey 50(1): 104111.

Wagner RH (1993) The Causes of Peace. In: Licklider R (ed.), Stopping the Killing: How Civil Wars End, New York: New York University Press, pp. 235-268.

Wilner AS (2010) Targeted Killings in Afghanistan: Measuring Coercion and Deterrence in Counterterrorism and Counterinsurgency. Studies in Conflict \& Terrorism 33(4): 307-329.

Wood RM and Kathman JD (2014) Too Much of a Bad Thing? Civilian Victimization and Bargaining in Civil War. British Journal of Political Science 44(03): 685-706.

Zussman A and Zussman N (2006) Assassinations: Evaluating the Effectiveness of an Israeli Counterterrorism Policy Using Stock Market Data. Journal of Economic Perspectives 20(2): 193206. 